\title{
Geochemical Characterization and Suitability of Surface and Sub-surface Waters for Irrigation in Lake Chala Catchment Area, Kenya
}

\author{
Josphat K. Mulwa \\ Department of Geology, University of Nairobi, P.O. Box 30197, Nairobi, Kenya
}

Received July 27, 2020; Revised September 15, 2020; Accepted September 29, 2020

\begin{abstract}
Cite This Paper in the following Citation Styles
(a): [1] Josphat K. Mulwa, "Geochemical Characterization and Suitability of Surface and Sub-surface Waters for Irrigation in Lake Chala Catchment Area, Kenya," Universal Journal of Geoscience, Vol. 8, No. 3, pp. 45 - 53, 2020. DOI: 10.13189/ujg.2020.080301.
\end{abstract}

(b): Josphat K. Mulwa (2020). Geochemical Characterization and Suitability of Surface and Sub-surface Waters for Irrigation in Lake Chala Catchment Area, Kenya. Universal Journal of Geoscience, 8(3), 45 - 53. DOI: 10.13189/ujg.2020.080301.

Copyright $\bigcirc 2020$ by authors, all rights reserved. Authors agree that this article remains permanently open access under the terms of the Creative Commons Attribution License 4.0 International License

\begin{abstract}
Lake Chala is a transboundary fresh water lake characterized by lack of effluent surface drainage and is located in southwestern Kenya on the Kenya-Tanzania border. This is a semiarid region frequently facing severe water scarcity especially during drought seasons. The major economic activities undertaken within the lake's catchment area include small-scale rain fed agriculture, which accounts for about $75-80 \%$ of household income. Over reliance on rain-fed agriculture has often had negative impacts on the people in this area due to water scarcity occasioned by unreliable rains. As such, there is need to tap the lake water for irrigation purposes. In order to determine the geochemical characteristics and suitability of the lake's catchment waters for irrigation purposes, water samples were collected on the Kenya and Tanzania sides of Lake Chala from eleven (11) sites in March 2011 and subjected to analysis for chemical characteristics. Based on hydro-chemical facies, ten water samples show that calcium-Magnesium-bicarbonate waters predominates in the catchment area, while one water sample from a shallow well is a calcium-magnesium-chloride type. The suitability of the water for irrigation purposes was evaluated based on sodium percent, residual sodium carbonate, sodium adsorption ratio and salinity hazard and found to be suitable for irrigation purposes. Crop type and soils may also have a profound influence on water suitability for irrigation. It is, therefore, herein recommended that further study be undertaken to evaluate the suitability of soils for
\end{abstract}

specific crop types. Keywords Chemical Characters, Chemical
Classification, Irrigation, Lake Chala, Kenya

\section{Introduction}

\subsection{Background Information}

Water in Kenya, like elsewhere in the world, is a crucial resource with great implications for socio-economic development since the country relies heavily on agricultural production. However, with an increasing population and expanding industrial sector, demand for water is constantly rising and this poses the challenge of managing the meager available water resources in a sustainable way in order to meet the country's water demand [1]. Kenya is currently classified as a net water deficit country and is among the category of water stressed countries that have to deal with chronic water shortage. She has a natural fresh water supply of only $647 \mathrm{~m}^{3}$ per person, which is expected to fall to $245 \mathrm{~m}^{3}$ in 2025 . The water scarcity has intensified competition among various water users. Independent of climate change, this situation will exacerbate owing to population growth, degradation of water towers caused by land use change, siltation of 
river basins and climate change among other factors. It has been estimated that Kenya has 19,500 million cubic meters $\left(\mathrm{Mm}^{3}\right)$ of renewable surface water and 619 million cubic meters $\left(\mathrm{M} \mathrm{m}^{3}\right)$ of ground water potential. The total annual demand is, however, estimated to be $3,874 \mathrm{M} \mathrm{m}^{3}$ in 2000 but expanding very rapidly [2]. Accessibility to water resources is relatively low in the country estimated at $45 \%$ with $33 \%$ in the rural areas. The low access to water resources is exacerbated by its poor distribution and variable quality due to perennial overdrafts and industrial pollution of water sources.

Contamination of freshwater supplies is a major problem in agricultural areas due to the increased dependence on agrochemicals. Fertilizers enriched in nitrates, phosphates, potassium, and non-fertilizers in form of pesticides, fungicides and herbicides are used to increase agricultural productivity and food capacity to meet rising population demand at both domestic and industrial level, thereby ensuring food security and nutrition, which is one of Kenya's Big four agenda. In addition, plummeting productivity in irrigated areas because of water logging, soil salinity rise due to rising water tables in irrigated areas has increased the use of agrochemicals with little attention given to surface and sub-surface water contamination.

The capacity for water resources to meet the various needs has been over-stressed and this has led to its scarcity. Various reasons can be advanced for this and they relate to population increase, climate change, environmental degradation, weak and inadequate institutional capacities, and the growing poverty levels in the country. The rapid population increase has subjected the limited available water resources to a lot of pressure in efforts to meet the various needs. Climatic variability and change has also significantly altered the rainfall patterns and amounts, thereby affecting the replenishment rate of water bodies [1]. These, coupled with wanton environmental degradation (especially in the main water catchments), changing land use patterns, wastage, misuse and pollution, the water problem has become even more critical. This is evidenced by the drying up of rivers, sedimentation and receding or dwindling lake levels [3,4], siltation of dams such that they cannot hold the expected capacities, and degradation of water qualities in many sources [5].

In view of the discussion in the preceding paragraphs, water quality analysis is one of the most important aspects in water studies. Geochemical analysis for its characterization and subsequently water quality evaluation often reveals the quality of water that is suitable for domestic consumption, agriculture and industrial purposes, as well as aiding in management of the water resources. Furthermore, it is possible to understand the change in water quality due to rockwater interaction or anthropogenic influence. Water often consists of seven major chemical ions which include cations $\mathrm{Ca}^{2+}, \mathrm{Mg}^{2+}, \mathrm{Na}^{+}, \mathrm{K}^{+}$and anions $\mathrm{Cl}^{-}, \mathrm{HCO}_{3}{ }^{-} \mathrm{SO}_{4}{ }^{2-}$. In addition, other ions include $\mathrm{Fe}^{3+}, \mathrm{Pb}^{2+}$,
$\mathrm{Mn}^{2+}, \mathrm{Cr}^{2+}, \mathrm{Zn}^{2+}, \mathrm{Cd}^{2+}, \mathrm{NO}_{3}^{-}, \mathrm{NO}_{2}^{-}, \mathrm{Cl}^{-}$, and $\mathrm{F}^{-}$(Islam et al. 2014; Fetter 2018). Other parameters include pH, Colour, Turbidity, Free Carbon Dioxide and Total Dissolved Solid. These chemical parameters play a significant role in classification and assessment of water quality. Apart from $\mathrm{Pb}^{2+}, \mathrm{Cr}^{2+}, \mathrm{Zn}^{2+}$ and $\mathrm{Cd}^{2+}$, all the other ions and parameters were analyzed in the water samples from Lake Chala and environs. Considering the individual and paired ionic concentration, certain indices are proposed to find out the alkali hazards. Residual sodium carbonate (RSC) can be used as a criterion for finding the suitability of irrigation waters. It was observed that the criteria used in the classification of waters for a particular purpose considering the individual concentration may not find its suitability for other purposes and better results can be obtained only by considering the combined chemistry of all the ions rather than individual or paired ionic characters [6-8]. Chemical classification also throws light on the concentration of various predominant cations, anions and their interrelationships. A number of techniques and methods have been developed to interpret the chemical data.

Reference [9] has summarized the various modes of data representation and discussed their possible uses. Presentation of chemical analysis data in graphical form makes understanding of complex water resource systems simpler and quicker. Methods of representing the chemistry of water like Collin's bar diagram [8], radiating vectors [10], and parallel and horizontal axes [11] have been used in many parts of the world to show the proportion of ionic concentration in individual samples.

The main objective of the present work therefore was to study critically and discuss the major ion chemistry of surface and groundwater of Lake Chala and surrounding environs using methods proposed by [12-18] among others.

\subsection{The Study Area}

Lake Chala is a transboundary water resource located within Lake Chala catchment area in the southwestern part of Kenya. The catchment area is approximately bound by latitudes 30 9' 00" and $3025^{\prime}$ '30" South and longitude 370 $30^{\prime} 00^{\prime \prime}$ and $37046^{\prime} 30^{\prime \prime}$ East (Figure 1). The lake has a surface area of approximately $4.2 \mathrm{~km}^{2}$ where else that of the catchment area is about $16.23 \mathrm{~km}^{2}$. The catchment area straddles Kenya and Tanzania and the lake is located about $9.65 \mathrm{~km}$ North of Taveta town. It forms a trans-boundary water resource shared between Kenya and Tanzania (Figures 1 and 2). The lake is a crater lake formed from a paroxysmal volcanic outburst [19] and has a surface area of $4.2 \mathrm{~km}^{2}$ within a surface catchment area of about $16.23 \mathrm{~km}^{2}$. According to [19], the inner walls of the lake are inclined at an angle of approximately $45^{\circ}$ and the depth is estimated to be about 91.44 meters. The lake is enclosed by a ridge with a surface elevation of 952 meters above sea level (masl) while the elevation of the water level is 854 masl. This translates to a vertical descent of about $98 \mathrm{~m}$ from the ridge surface to the lake water level. 
The hydrogeology of Lake Chala catchment area is defined by the Kilimanjaro aquifer delineated by Grossmann (2008). The aquifer is comprised of volcanic pyroclastics and volcanic alluvium deposits, which occur at the base of Mt Kilimanjaro and extend across the Kenyan-Tanzanian border [20]. These deposits form basins which extend outward from the mountain and are limited by the surrounding Precambrian basement rocks. Occurrence of groundwater in the surrounding basement plains is limited to faults, fractures and small parts of weathered zones and also to the bottom layers of wide alluvial valleys which are recharged by natural flood spreading [20].

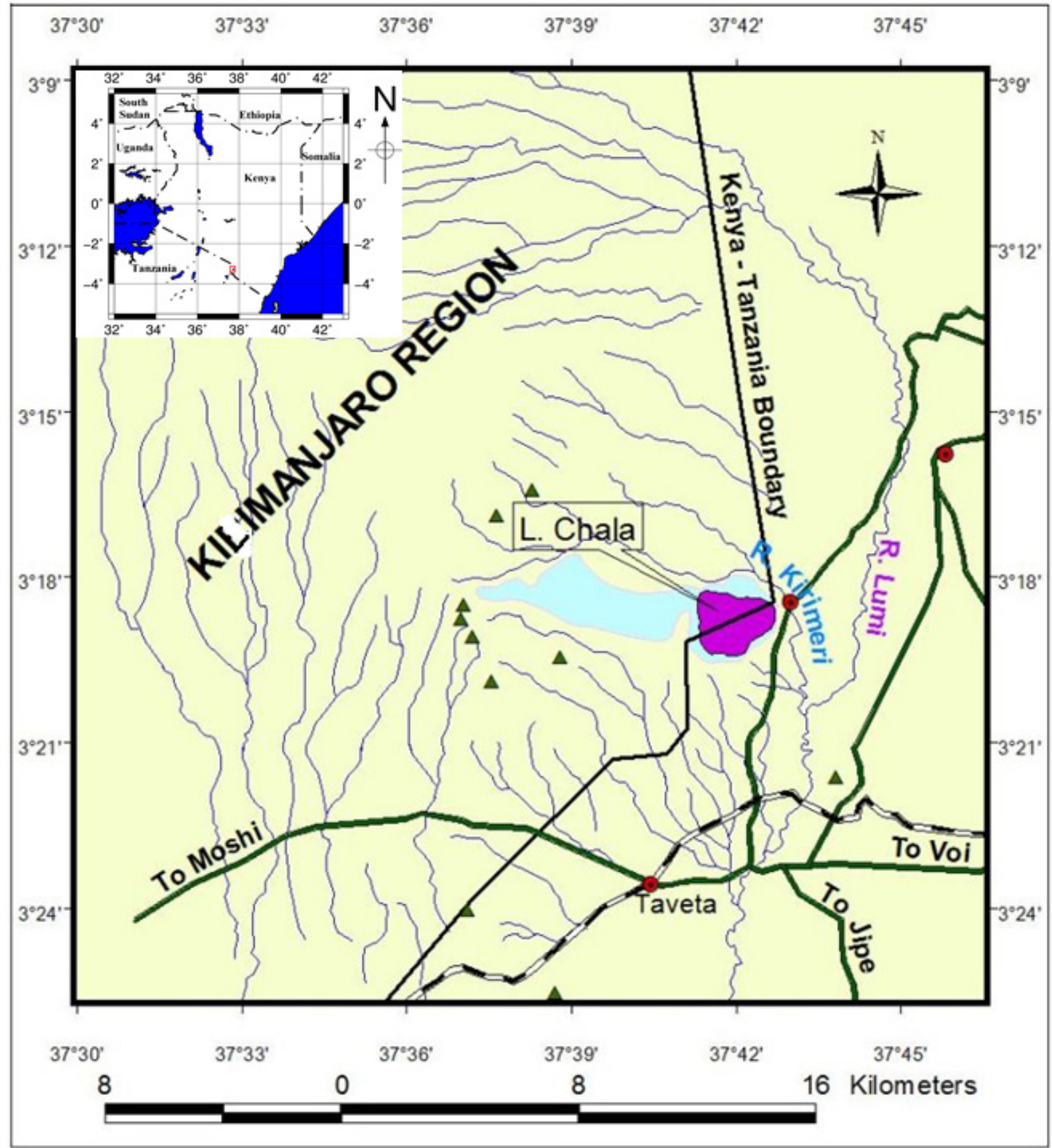

Figure 1. Location of Lake Chala and its catchment area straddling Kenya and Tanzania. The study area in outlined by red square in the inset map 


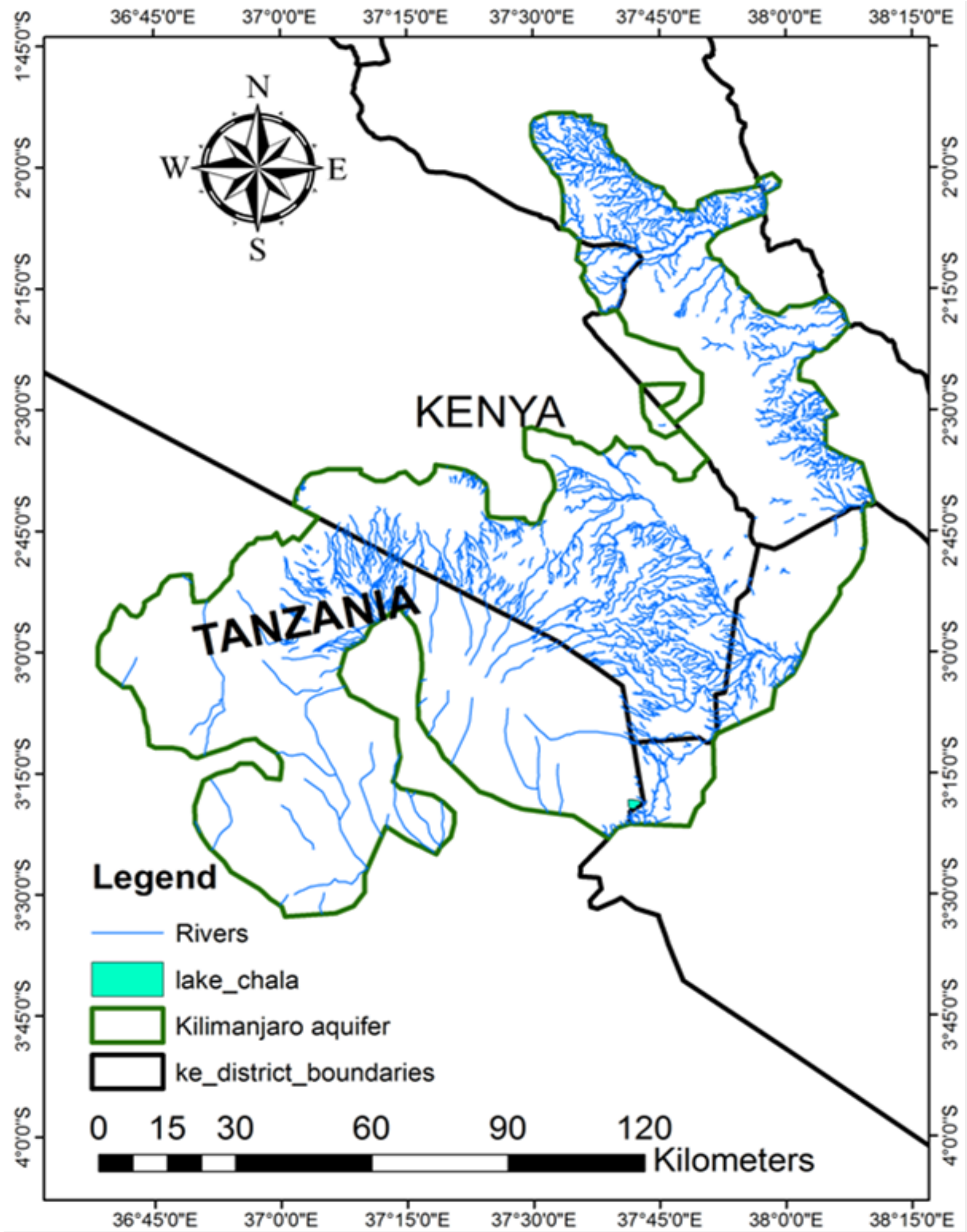

Figure 2. Extent of Kilimanjaro aquifer across the Kenya-Tanzania border (Modified from Grossmann 2008)

The basement rocks are an aquiclude for a large regional groundwater flow system emanating from Kilimanjaro, which extends into the volcanic alluvium at the base of the mountain and forms major aquifers. These basins are filled by alluvium deposits composed of sand, gravel and clay, with calcareous deposits, some lava and pyroclastic volcanic rocks [20].

Water from the regional groundwater flow systems within the Kilimanjaro mountain reaches the aquifers and high yielding springs at the base of the mountain in two ways: by diffuse flow and by concentrated flow. Three major geological features determine the formation of 
springs for the Kilimanjaro aquifer, these include, in-fills of paleo-valleys, fault zones in fractured rocks, and lateral aquifers characterized by porous rocks or sedimentary materials [21]. Although aquifers of the first two types have a limited spatial extent and springs emerge from them at isolated points, lateral aquifers are often extensive and characterized by a series of springs and swamps (Figure 3). Lake Chala is part of the extensive Kilimanjaro aquifer and, even though it does not have visible inlet or outlet, its recharge and discharge are strongly linked to the volcanic pyroclastics and volcanic alluvium deposits, which allow percolation through faults, fractures and weathered zones [20].

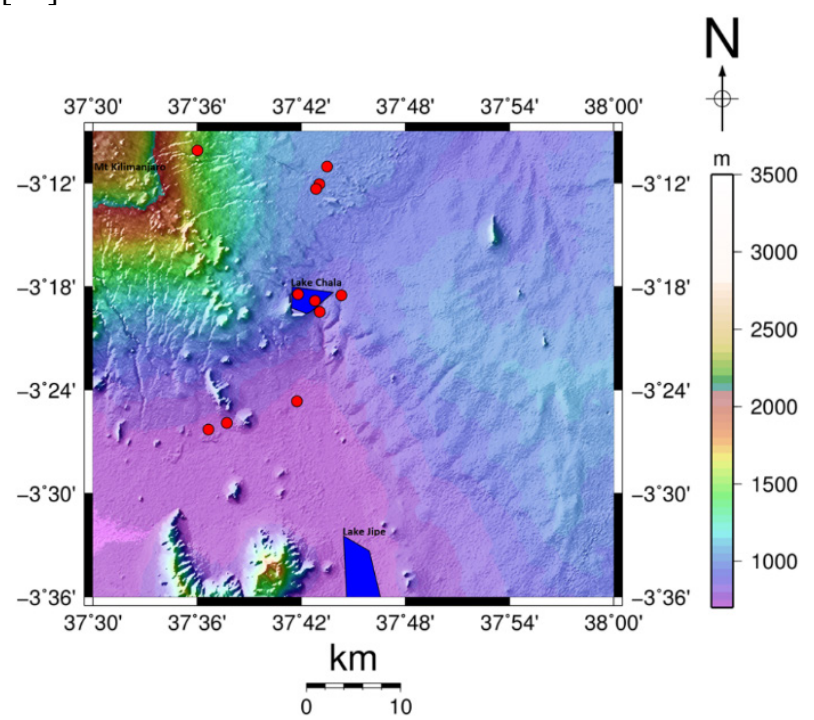

Figure 3. Springs within Lake Chala catchment area sampled for water chemical analysis

\section{Materials and Methods}

In order to determine the chemical characteristics and the suitability of surface and ground waters for irrigation and domestic use, water sampling in Lake Chala catchment area was conducted in March 3, 2011. The water sample collection and chemical description was undertaken in line with the field sampling procedure for Texas Water Development Board [22]. Eleven water samples were collected from Lake Chala, boreholes, shallow wells, springs and Lumi river, with two water samples being collected from the lake on the Kenyan and Tanzanian sides as shown in Figure 4 and Table 1.

Pre-cleaned plastic bottles rinsed with distilled water were used for collection of water samples. The water samples for the analysis of cations were filtered through a $0.45 \mu \mathrm{m}$ filter. Each sampling bottle was totally filled with the respective water sample and carefully closed tightly for dispatch to the central water-testing laboratory of the Ministry of Water and Sanitation for analysis of chemical characters. Chemical analyses was carried out in order to determine the major ionic concentrations of the water samples collected from different locations using the standard procedure recommended by American Public
Health Association [23]. Such analytical data can be used to elucidate the chemical character of water for utilitarian purposes and for ascertaining various factors for which the chemical characteristics of the water are dependent upon.

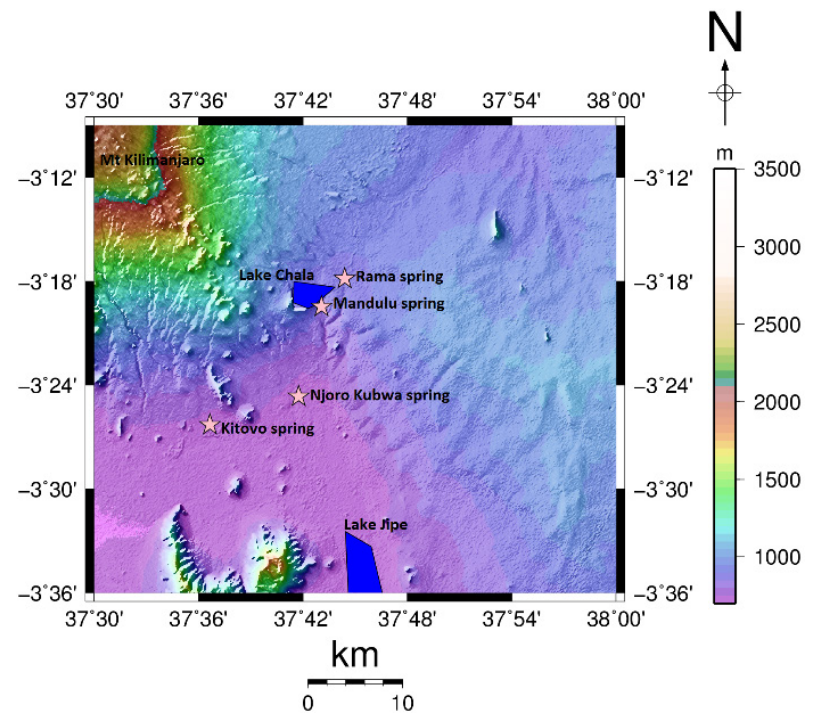

Figure 4. Water sampling locations within Lake Chala catchment area

In addition to the major ions, the water $\mathrm{pH}$, conductivity (Eh) and total alkalinity were determined at the time of sampling in order to avoid the effect of dissociation especially of carbon (IV) oxide during the holding time that may cause analytical errors and thereby significantly affect the total alkalinity. Since alkalinity is controlled by dissolution or degassing of carbon (IV) oxide, this is likely to shift the source of alkalinity. Consequently, total alkalinity as $\mathrm{CaCO}_{3}$ - bicarbonate test procedure and Phenolphthaleian alkalinity as $\mathrm{CaCO}_{3}$ - carbonate test procedure were used to measure alkalinity.

Once the chemical analysis of the water samples was undertaken, the Piper tri-linear diagram [12 was used to infer hydrogeochemical facies of the water in Lake Chala and surrounding environs. According to [17], the trilinear diagram includes two triangles, one for plotting the percentage composition of the major cations and the other for plotting the percentage composition of the major anions. In these triangles, $\mathrm{Na}^{+}$and $\mathrm{K}^{+}$are grouped together while $\mathrm{CO}_{3}{ }^{2-}$ and $\mathrm{HCO}^{-}$are likewise grouped together [17]. The cation and anion fields for each of the respective water samples are then combined to show a single point in a diamond-shaped field from which inference of the hydro-chemical facies is drawn to describe water sources that differ in their chemical composition [17]. This diamond-shaped field is also used to represent water-type categories [18] that form the basis for one common classification scheme for natural water. Using the Piper-trilinear diagram, evolution pathways or mixing of different sources of water can also be illustrated. Consequently, piper tri-linear diagrams are useful in bringing out chemical relationships among water samples in more definite terms than with other possible plotting methods. 
Table 1. Water sampling locations and sample types from Lake Chala catchment area

\begin{tabular}{|c|c|c|c|}
\hline Longitude (East) & Latitude (South) & Location & Water sample type \\
\hline 37.713042 & 3.313751 & Lake Chala (Kenya) & Lake \\
\hline 37.696938 & 3.307386 & Lake Chala (Tanzania) & Borehole \\
\hline 37.724691 & 3.184299 & Njukini Primary School & Borehole \\
\hline 37.714002 & 3.205722 & Bishop Njenga Secondary School & Shallow well \\
\hline 37.738646 & 3.308755 & Mutinda well & Shallow well \\
\hline 37.628269 & 3.431884 & Reate well & Spring \\
\hline 37.717570 & 3.324420 & Mandulu spring & Spring \\
\hline 37.695960 & 3.410960 & Njoro Kubwa spring & River \\
\hline 37.610664 & 3.438353 & Kitovo spring & River \\
\hline 37.600170 & 3.168635 & Lumi river (Tanzania) & Lumi river (Kenya) \\
\hline 37.717454 & 3.201204 & & \\
\hline
\end{tabular}

\section{Results}

The maximum and minimum concentrations of the major ions present in waters from Lake Chala and surrounding environs are presented in table 2 . Chemical data of the water samples from the study area has been grouped into four groups and represented by plotting them on Piper tri-linear diagram in Figure 5. The four groups of water samples include Lake Chala, boreholes, wells, springs and rivers. The regions delineated by letters in Fig 5 show the major-ion percentages as follows: A-Calcium type; B-No dominant ion type; C-Magnesium type; D-Sodium and potassium type; E-Bicarbonate type; F-Sulphate type; and G-Chloride type.

From the results presented in figure 5, no cation is dominant in the water samples, while for anions, ten samples are of bicarbonate type and only one sample is of chloride type. The hydrochemical facies of the water samples from Lake Chala catchment area is deduced from the diamond shaped field of the piper tri-linear diagram (according to subdivisions suggested by [18]. From figure 5 , the various hydrochemical facies are classified on the basis of numbers 1-9 as follows: 1- Alkali earth metals $(\mathrm{Ca}+\mathrm{Mg})$ exceed alkali metals $(\mathrm{Na}+\mathrm{K})$; 2-Alkali metals exceed alkali earth metals; 3-Weak acids $\left(\mathrm{CO}_{3}+\mathrm{HCO}_{3}\right)$ exceed strong acids $\left(\mathrm{SO}_{4}+\mathrm{Cl}\right)$; 4-Strong acids exceed weak acids; 5-Magnesium bicarbonate type; 6-Calcium chloride type; 7-Sodium chloride type; 8-Sodium bicarbonate type; and 9-Mixed type where no cation-anion exceeds $50 \%$. Upon this basis, the hydrochemical facies of ten water samples from Lake Chala catchment area is of calcium-magnesium-bicarbonate type and only one sample is of calcium-magnesium-chloride type. The calcium-magnesium-chloride type water was from an open well which apparently has the highest concentrations of $\mathrm{Ca}$ $(76.8 \mathrm{mg} / \mathrm{l}), \mathrm{Mg}(41.3 \mathrm{mg} / \mathrm{l}), \mathrm{Na}(109 \mathrm{mg} / \mathrm{l}), \mathrm{CO}_{3}(282$ $\mathrm{mg} / \mathrm{l}), \mathrm{Cl}(205 \mathrm{mg} / \mathrm{l}), \mathrm{SO}_{4}(16.9 \mathrm{mg} / \mathrm{l})$, total hardness (382 $\mathrm{mg} / \mathrm{l})$ and total dissolved solids $(746.5 \mathrm{mg} / \mathrm{l})$ in the study area.
Table 2. Maximum and minimum concentrations of major ions in water samples from Lake Chala catchment area

\begin{tabular}{|c|c|c|}
\hline \multirow{2}{*}{ Ions } & \multicolumn{2}{|c|}{ Concentration (mg/l) } \\
\cline { 2 - 3 } & Minimum & Maximum \\
\hline $\mathrm{Na}^{+}$ & 5.5 & 109.0 \\
\hline $\mathrm{K}^{+}$ & 0.0 & 0.6 \\
\hline $\mathrm{Ca}^{2+}$ & 6.4 & 76.8 \\
\hline $\mathrm{Mg}^{2+}$ & 2.43 & 41.3 \\
\hline $\mathrm{CO}_{3}{ }^{2-}$ & 0.0 & 282.0 \\
\hline $\mathrm{HCO}_{3}{ }^{-}$ & 0.0 & 190.0 \\
\hline $\mathrm{Cl}^{-}$ & 3.0 & 205.0 \\
\hline $\mathrm{SO}_{4}{ }^{2-}$ & 0.3 & 16.9 \\
\hline Total hardness & 26.0 & 362.0 \\
\hline Total Dissolved & 47.43 & 746.5 \\
\hline Solids (TDS) & & \\
\hline
\end{tabular}

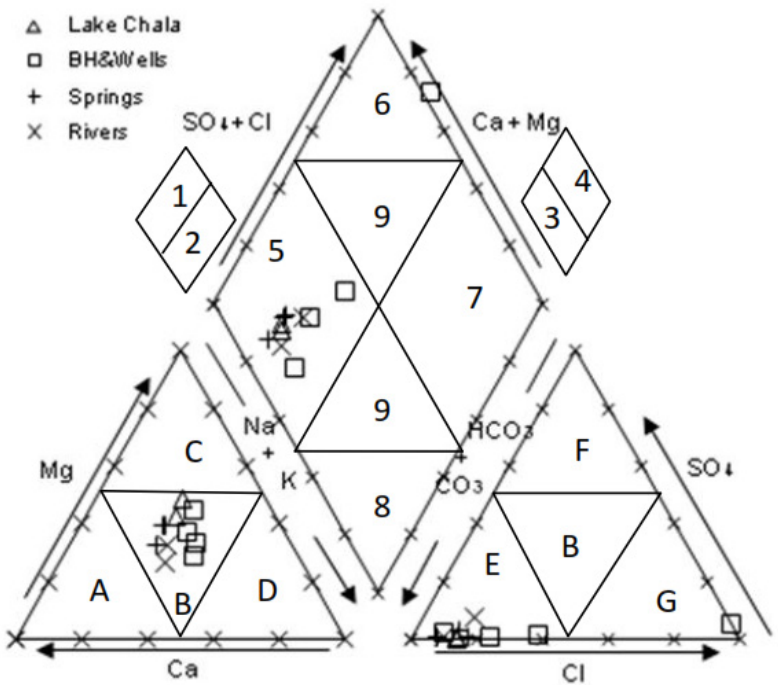

Figure 5. Water sample compositions plotted on Piper tri-linear diagram

\section{Discussion}

The presence of cations such as calcium and magnesium and anions such as carbonate, bicarbonate, chloride and 
sulphate causes hardness in water. Even though hard water is beneficial to health and has no known adverse effects, some evidence indicates its role in heart disease [24]. Hard water is unsuitable for domestic use since it requires more soap for effective cleaning, forms scum and curd, causes yellowing of fabrics, toughens vegetables cooked in the water and forms scales in boilers, water heaters, pipes and cooking utensils. On the other hand, naturally too soft water may be corrosive. In Lake Chala catchment area, the total hardness varies between 26 to 362 $\mathrm{mg} / \mathrm{l}$. According to [25], the hardness of good quality water should not exceed $270 \mathrm{mg} / \mathrm{l}$. In Lake Chala catchment area, the total hardness of water from the open well is the only one which exceeds the $270 \mathrm{mg} / \mathrm{l}$ threshold. According to the hardness classification by [26], three samples fall under soft, hard and very hard classes, while eight samples fall under moderately hard class.

The suitability of water for irrigation purposes is dependent on its mineral constituents. Several criteria for judging its suitability have been proposed and are based on criteria by $[14,15]$. These criteria include (i) Total salt concentration as measured by electrical conductivity, (ii) Relative proportion of sodium as expressed by SAR to other principal cations, (iii) Bicarbonate, and (iv) Boron. According to [14], the United States Salinity Laboratory of the Department of Agriculture adopted certain techniques on the basis of which the suitability of water for agriculture is intended. The sodium content in irrigation waters is then expressed as percent sodium (also known as sodium percentage and soluble-sodium percentage) which can be determined using the equation by [16] as follows:-

$$
\% \mathrm{Na}=\frac{\left(\mathrm{Na}^{+}+\mathrm{K}^{+}\right) * 100}{\mathrm{Ca}^{++}+\mathrm{Mg}^{++}+\mathrm{Na}^{+}+\mathrm{K}^{+}}
$$

where the concentrations of ionic species are in milliequivalents per liter (meq/1).

Water for domestic and irrigation purposes has been classified based on the percentage of sodium [14] as shown in table 3. The sodium percentage in water from Lake Chala catchment area varies between $24.65 \%$ - 39.65\%. Based on the values of sodium percentage presented in table 3 , the water from Lake Chala catchment area is hereby categorized as good for irrigation purposes.

Table 3. Classification of water based on sodium percentage [14]

\begin{tabular}{|c|c|}
\hline Sodium (\%) & Water class \\
\hline$<20 \%$ & Excellent \\
\hline $20-40$ & Good \\
\hline $40-60$ & Permissible \\
\hline $60-80$ & Doubtful \\
\hline$>80$ & Unsuitable \\
\hline
\end{tabular}

Residual Sodium Carbonate (RSC) is another factor that has be used to determine the suitability of water from Lake Chala catchment area for irrigation purpose. RSC is attributed to increase in sodium carbonate in waters having high concentration of bicarbonate due to precipitation of calcium and magnesium salts as the water in soil becomes more concentrated in sodium carbonate. The RSC is calculated using the equation:

$$
\mathrm{RSC}=\left(\mathrm{HCO}_{3}^{-}+\mathrm{CO}_{3}^{-{ }^{-}}\right)-\left(\mathrm{Ca}^{++}+\mathrm{Mg}^{++}\right)
$$

where the concentrations of ionic species are in milliequivalents per liter (meq/l). According to [14], water having more than $2.5 \mathrm{meq} / \mathrm{l}$ of $\mathrm{RSC}$ is unsuitable for irrigation purposes.

The RSC of ten water samples from Lake Chala catchment area are less than zero varying between -2.72 and -0.09 where else one water sample from a shallow well has an RSC value of 1.91. Based on the RSC values, the sampled water sources in Lake Chala catchment area including Lake Chala are excellent for irrigation purposes and no hazard is likely since the negative RSC values from ten water sources indicates that sodium buildup is unlikely as sufficient calcium and magnesium are in excess of what can be precipitated as carbonates, with consequent removal of calcium and magnesium from the irrigation water leaving the sodium carbonate to accumulate.

The suitability of water for irrigation purposes can also be determined by the sodium hazard or Sodium Adsorption Ratio (SAR). SAR is calculated using the equation $[16,17$, 27]

$$
\mathrm{SAR}=\frac{\mathrm{Na}^{++}}{\left(\mathrm{Ca}^{++}+\mathrm{Mg}^{++} / 2\right)^{1 / 2}}
$$

where all ionic concentrations are expressed in milliequivalents per liter (meq/l).

Reference [14] has classified water for irrigation purposes with respect to $\mathrm{SAR}$ as excellent if $\mathrm{SAR}<10$ and unsuitable if $\mathrm{SAR}>26$. Intermediate range of $\mathrm{SAR}$ varies between 10 to $<18$ (good) and 18 to $<26$ (doubtful). Upon this basis, the SAR values of water in Lake Chala catchment varies between 0.5 (minimum) to 2.5 (maximum) and is therefore excellent for irrigation purposes.

Water may also be classified on the basis of specific conductance (EC) which is dependent on the total concentration of soluble salts or salinity hazard [27-29] as shown in table 4

Table 4. Categories of salinity hazard of water quality based on electrical conductance [30]

\begin{tabular}{|c|c|c|}
\hline $\begin{array}{c}\text { Salinity hazard } \\
\text { class }\end{array}$ & EC $(\boldsymbol{\mu S} / \mathbf{c m})$ & Remark on quality \\
\hline Class 1 & $100-250$ & Excellent \\
\hline Class 2 & $251-750$ & Good \\
\hline Class 3 & $751-2000$ & Permissible \\
\hline Class 4 & $2001-3000$ & Doubtful \\
\hline Class 5 & $>3000$ & Unsuitable \\
\hline
\end{tabular}

The classification of water in Lake Chala catchment area 
based on salinity hazard as shown in table 4 demonstrate that the water falls under three classes of salinity hazard. Two water samples from Lake Chala on the Kenyan and Tanzanian sides have EC values of 382 and $383 \mu \mathrm{S} / \mathrm{cm}$. In addition, two samples from two boreholes, one sample from a well and two samples from two springs have EC values of 266 and $400 \mu \mathrm{S} / \mathrm{cm}, 577 \mu \mathrm{S} / \mathrm{cm}$, and 235 and 394 $\mu \mathrm{S} / \mathrm{cm}$ respectively. Two river samples and a further one spring sample have EC values of 76.5, 224 and $235 \mu \mathrm{S} / \mathrm{cm}$ respectively. Out of the eleven water samples, only one sample from a shallow well has an EC value of $1204 \mu \mathrm{S} / \mathrm{cm}$. From the classification of water on the basis of salinity hazard presented in table 4 , ten water sources fall under classes 1 and 2 and are therefore considered as excellent to good for irrigation purposes. Water sample from the shallow well where the EC value exceeds $1000 \mu \mathrm{S} / \mathrm{cm}$ falls under class 3 and is hereby considered as being of permissible quality for irrigation purposes.

\section{Conclusions}

Water sampling in Lake Chala catchment area has been carried out in order to evaluate its chemical character and its suitability for irrigation use. Based on the hydrochemical facies, the type of water that predominates in Lake Chala catchment area is calcium-magnesium-bicarbonate $\left(\mathrm{Ca}-\mathrm{Mg}-\mathrm{HCO}_{3}\right)$. One shallow well, however, is characterized by calcium-magnesium-chloride $(\mathrm{Ca}-\mathrm{Mg}-\mathrm{Cl})$ type of water. The suitability of water for irrigation purposes has been determined in this study based on sodium percentage $(\% \mathrm{Na})$, residual sodium carbonate (RSC), sodium adsorption ratio (SAR) and salinity hazard. This, however, is an empirical conclusion since in addition to water quality, other factors like soil type, crop type, crop pattern, rainfall frequency, recharge and climate among others play an important role in determining the suitability of the water for irrigation purposes. Depending on the soil type classification, for example, unsuitable water for irrigation purposes based on the chemical characteristic may be suitable if the soils are well drained. The suitability of water for irrigation in Lake Chala catchment area as evaluated based on $\% \mathrm{Na}$, RSC, SAR and salinity hazard is good with respect to \%Na, excellent with respect to RSC and SAR values and, good to excellent with respect to salinity hazard, apart from only one water sample from a shallow well. The water is therefore generally suitable for irrigation purposes.

\section{Recommendation}

As outlined in the preceding section, other factors like soil type, crop type, crop pattern, rainfall frequency, recharge and climate play an important role in determining the suitability of the water for irrigation purposes. Of particular importance for Lake Chala are the soil and crop types if irrigation has to be undertaken. The water from Lake Chala catchment area has been categorized as good with respect to $\% \mathrm{Na}$, excellent with respect to RSC and SAR values and, good to excellent with respect to salinity hazard, apart from only one water sample from a shallow well. Nevertheless, it is herein recommended that, further studies be undertaken to evaluate the full suitability of the waters for irrigation based on the soil and crop types.

\section{Acknowledgements}

The author would like to acknowledge Coast Water Works Development Agency (CWWDA), formerly Coast Development Authority (CDA) and Mr. Reshamta of CWWDA office in Taveta town for funding analysis of the water samples and assistance during the fieldwork respectively. The government of the Republic of Tanzania through Pangani River Basin allowed unconditional access and collection of water samples on the Tanzanian side and is hereby deeply acknowledged. Many thanks to elder Rama, a resident of Taveta, for providing useful background information and history about Lake Chala. Finally but yet importantly, I acknowledge an anonymous peer reviewer whose constructive criticism enabled refinement of the manuscript.

\section{REFERENCES}

[1] S.M. Kithiia. Integrated Water Resources Management in the wake of Climate Change Scenario in Kenya, PhD Thesis, University of Nairobi, Kenya, 2012.

[2] National Environment Management Authority (NEMA). State of the Environment Report, Kenya, Government Printer, 2003.

[3] G.M. Ashley, J.M. Mworia, A.M. Muasya, R.B. Owen, S.G. Driese, V.C. Hover, R.W. Renaut, M.F. Goman, S. Mathai, S.H. Blatt. Sedimentation and recent history of a freshwater wetland in a semi-arid environment: Loboi swamp, Kenya, East Africa, Sedimentology, Vol. 51, 1-21, 2004.

[4] L.A. Olaka, E.O. Odada, M.H. Trauth, D.O. Olago. The sensitivity of East African rift lakes to climate fluctuations, J. of Paleolimnology, Vol. 44, No. 2, 629-644, 2010.

[5] UN-Water. Coping with water scarcity: challenge of the $21^{\text {st }}$ century. World Water Day 2007, Stockholm, Sweden, 2007, http://www.unwater.org/wwd07/downloads/ documents/escarcity.pdf, Cited 2 February 2020).

[6] B.K. Handa. Modified classification procedure for rating irrigation waters, Soil Sci., Vol. 98, 264-269, 1964.

[7] B.K. Handa. Modified Hill-piper diagram for presentation of water analysis data, Curr Sci, Vol. 34, 131-134, 1965. 
[8] J.D. Hem. Study and interpretation of chemical characteristics of natural water, United States Geological Survey Water Supply Paper, Vol. 2254, 117-120, 1985.

[9] A. Zaporozec. Graphical interpretation of water quality data, Groundwater, Vol. 10, No. 2, 32-43, 1972.

[10] R. Maucha. The graphical symbolization of the chemical composition of natural waters, Hidrológiai Közlöny, Vol. 13, 117-118, 1949.

[11] H.A. Stiff Jr. The interpretation of chemical water analysis by means of patterns, J Petrol Technol., Vol. 3, 15-16, 1940.

[12] A.M. Piper. A graphic procedure in the geochemical interpretation of water analyses, Am Geoph. Union Trans., Vol. 25, 914-923, 1944.

[13] L.V. Wilcox. The quality of water for irrigation use, U.S. Department of Agriculture, Technical Bulletin 1962, Washington D.C., U.S.A., 1948.

[14] L.V. Wilcox. Classification and use of irrigation waters, U.S. Department of Agriculture, Circular No. 969, Washington D.C. U.S.A, pp. 19, 1955.

[15] F.M. Eaton. Significance of carbonates in irrigation waters, Soil sci., Vol. 69, No. 2, 123-134, 1950.

[16] D.K. Todd, L.W. Mays. Groundwater Hydrology, John Wiley and Sons Inc., 2005.

[17] C.W. Fetter. Applied Hydrogeology, Prentice Hall Inc.,
2001.

[18] W. Back, B.B. Hanshaw. Chemical geohydrology, In Chow VT (ed), Advances in Hydroscience, Academic Press, New York, pp 49-109, 1965

[19] L.M. Bear. Geology of the Taveta area, Geological Survey of Kenya, Report No. 32, 1955.

[20] M. Grossmann. The Kilimanjaro Aquifer, a case study for the research project "Transboundary groundwater management in Africa", German Development Institute (DIE), Bonn, Germany. pp 91-124, 2008.

[21] P.Z. Yanda, S. Mpanda. Spring Water Discharge Variability on the Footslopes of Mount Kilimanjaro, In: Water Management in Pangani River Basin (Chapter 2), Research Monograph, Vol. 1, http://hdl.handle.net/123456789/871, 2001.

[22] R.P.G. Boghici. A field manual for groundwater sampling, Texas Water Development Board (TWDB), User Manual, pp 47, 2003.

[23] American Public Health Association (APHA). Standard methods for examination of water and wastewater, American Public Health Association (APHA), American Water Works Association (AWWA), Water Environment Federation (WEF), pp 46, 1999.

[24] H.A. Schroader. Relations between hardness of water and death rates from certain chronic and degenerative diseases in the United States, J. Chron. Disease, Vol. 12, 586-591, 1960. 